Article

\title{
What Do We Still Need to Know about Employee Creativity: A fsQCA Approach
}

\author{
Yao Song ${ }^{1}$, Shikui Gao ${ }^{1, *}$, Yang Zhao ${ }^{2}$ and Sanjaya Singh Gaur ${ }^{3}$ \\ 1 School of Economics and Management, China University of Geosciences (Beijing), Xueyuan Road 29, \\ Haidian District, Beijing 100083, China; songyao@cugb.edu.cn \\ 2 Sunway University Business School, Sunway University, No. 5, Jalan University, Bandar Sunway, \\ 47500 Selangor Darul Ehsan, Malaysia; yangz@sunway.edu.my \\ 3 NYU School of Professional Studies, The New York University, 11W 42nd Street, New York, NY 10036, USA; \\ sonjaya.gaur@nyu.edu \\ * Correspondence: gaoshikui@cugb.edu.cn; Tel.: +86-010-8232-2051
}

Received: 4 December 2019; Accepted: 4 February 2020; Published: 5 February 2020

\begin{abstract}
This study explored employees behavior flexibility, status, and independence value as vital factors of employee creativity. Based on the theory of interaction creativity, we theorize the core factors, synergistic effects, and substitution effects of employee creativity. This paper adopted a qualitative approach using a self-administrated survey to collect data. Data were collected from 380 Chinese employees via an online and offline survey. The results contribute to creativity literature and expand the study on employee's creativity performance. Moreover, it opens the black box of employee creativity from a new insight by exploring the effects of human resource flexibility and work values. The paper suggests that to obtain innovation and organizational sustainability, companies should not only advocate human resource flexibility management but also combine the work values of employees.
\end{abstract}

Keywords: employee creativity performance; human resource flexibility; work values

\section{Introduction}

China's economic development has made remarkable achievements globally. To keep the economic development in good condition, China has put forward an innovation-driven development strategy, transforming all elements of innovation into productive forces, and further strengthening the sustainable development of China's economy. The sustainability not only includes the sustainable development of the ecological environment and resource subsystem but also contains that of the economic subsystem itself [1]. The sustainable development of the economy is considered to be an important part of the whole system [2]. As the micro-unit of economic development, enterprises significantly affect and determine the sustainable development of the economy and society. The sustainable development of enterprises is indispensable to the positive development of the country.

In 2019, China's GDP growth rate was $6.5 \%$, and the Chinese economy contributed $34 \%$ to the global economy, which is inseparable from China's increasingly sophisticated economic development system based on creativity research and development. Under the background of rapid economic development, employees' creativity performance provides more lasting power for the sustainable development of enterprises. Therefore, employees with high creativity performance seem vital for the operating of enterprises. Creativity is the fundamental driving force that can lead to the long-term survival of an organization [3]. Employees with high creativity performance possess the skill to invent new products or transform the traditional exiting pattern to better designed structures so that organizations can maintain competitiveness and sustainable development [4]. Only by continually stimulating employees' 
creativity performance can enterprises optimize, to the maximum extent, the value of their products and services to promote the sustainable development of their organizations [5]. Indeed, employee creativity performance also leads to positive organizational performance. The sustainable development of an organization is closely related to optimal strategies, outstanding leaders, yet equally important is the design of the system and the training of employees. The essence of sustainable development of the economy is talent-driven. Sustainable development of enterprises cannot be separated from employees, and employees are the key and impetus source of corporate innovation [6], and the source of corporate innovation, especially those who have a good creative ability and thoughts. Employees with high creativity performance will contribute to the organization's sustainable development [7] because they can provide the creative thoughts and active work inspiration to produce a creative outcome. Human resources are acknowledged to be among the most valuable assets for the organization's development. It is essential to develop a sound management system to significantly stimulate the enthusiasm of creative talents, thus promoting the sustainable development of the organization. The focus of this paper will fall on how to improve employee creativity performance.

Flexibility management is an important component of strategy of organization [8]. If organizations possess flexible reaction and adaptability to the environment and formulate systematic management practices [9], they will gain competitive advantages in a dynamic and ferocious environment. Human resource flexibility exerts a crucial role in organizational performance. Millman [10] coined the concept of human resource flexibility and defines it as the ability which encourages organizations to effectively and timely adapt to changes and multiple demands in the environment or organization. Organizations can obtain innovation by human resource flexibility as employees gain more autonomy and flexibility at work [11]. The focus of human resource flexibility is training employees' ability and thinking habits to flexibly adapt to the work environment, which is beneficial for creativity performance [12]. Human resource flexibility achieves creativity performance by enhancing employees' creative learning ability. Human resource flexibility propels employees to adapt to multiple positions and adjust working behaviors, maintain high innovation momentum, purpose, interests, and passion [13], which in turn improve employee creativity performance. Those companies that focus on flexible management can mobilize employees' initiative and activity to a large extent and consequently encourage employee creativity performance [14]. In addition to employees' diverse skills, flexible behavior, and appropriate management practices, Alder [15] considered that individual motivation could stimulate employee creativity performance. Work values, subject to intrinsic working beliefs and thoughts, guide employees to make different behavioral choices for established jobs [16]. Different values have different effects on employees' creativity behavior. Therefore, we incorporated employee work values into our research. At present, there is little research on the relationship between human resource flexibility and employee creativity performance, as well as the combination of human resources flexibility and work values to explore employee creativity performance. From the creativity interactionist perspective [17], we explored how human resource flexibility and work values stimulate employee creativity performance. Woodman [17] revealed that employee creativity performance is a complex phenomenon, which composed of creative skills, behavior, and creative situation. Therefore, it is essential to explore its influential factors synergistically. According to the set theory, the components of a system can be divided into core elements and auxiliary elements [18]. The core principle of set theory is studying different cases as configurations. The configuration means a specific combination of relevant conditions linked to the outcome [19]. It focuses on causal conditions contributing to an outcome, not on general patterns of association. From the perspective of set theory, it is to explore whether the set represented by the configuration of multiple conditions is a subset of the result set. The configuration analysis focuses on how the combination of the independent variables work at the different configurations based on the set theory. The fuzzy-set qualitative comparative analysis (FsQCA) method, which is rooted in the set theory, calculates the number of causal conditions through Boolean algebra, which is a formula for set operations and logical operations. Hence, we use FsQCA method, which is rooted in the set theory, to perform the configuration analysis to find out the core elements and different effective combination 
approaches to achieve employee creativity. There are three key aspects to analyzing this issue in this paper. The first is to find out the core factors that trigger employee creativity performance. The second is to explore the interacting effect of human resource flexibility and work values on employee creativity performance, which is the synergistic effect. The definition of synergy is a positive outcome deriving from the interrelations among the components. Obviously, it is not a single component that leads to the outcome [20], hence, there may be considerable value in better specifying the different ways in which synergies affect employee creativity performance. The third is to explore the substitution effects of impact factors. Some factors cannot coexist in the same configuration.

This study expects to provide essential assistance for employee creativity performance and assist in sustainable development by finding out the core element and synergistic effects of human resource flexibility and work values. First, it explores the relationship between human resource flexibility and employee creativity performance. We have not only proved that human resource flexibility can promote employee creativity performance, but also found the core factors by using the quantity analyzing method. Second, we considered the important role of work values in innovation and discussed the synergistic and substitution effects of different kinds of work values and human resource flexibility. Besides, this study also provides implications on innovation and development of smalland medium-sized enterprises. Managers can enhance the flexible management of employees, thus providing a better atmosphere to promote creativity performance and develop more sustainable human resource management.

\section{Literature Review}

\subsection{Human Resource Flexibility and Employee Creativitiy Performance}

Employee creativity performance refers to novel thoughts conceived by employees for generating, promoting, and executing job purposes, resulting in individual and organizational performance. Employees are the resources of sustainable innovation of an enterprise [21]. Employees' creativity performance, which reflects the enhancement of enterprises' innovation ability, is a crucial component of the sustainable development of enterprises [5]. Sustainable development of economic links to the creation of economy and well-being of future generations [22]. The sustainable development of enterprises is inseparable from transformation and upgrading. Employees with creative ability can help enterprises seize opportunities [23] and develop new technologies and break in new fields. Since the sustainable development of an organization is the ultimate goal, employee creativity performance plays a significant role in achieving this goal. At present, there are many kinds of research on the influencing factors of employee creativity. The methods they used in doing these studies were structural equation models and multiple regression analysis. Organizational culture or atmosphere [10], leadership [9], organization-based self-esteem [24], and technical solution knowledge [25] are believed to be the factors that can promote employee creativity performance in most research. Because of the high uncertainty, external environment, and globally high competition, organizations need to have a dynamic ability to cope with fierce challenges to seek sustainable development. In this case, human resource flexibility plays a more and more critical role in the functioning of the organization's strategy [26]. Thus, from the dynamic ability perspective, the relationship between human resource flexibility and organizational performance has been paid more attention [27].

As stated by Robert [28], flexible, free, and cooperative teams have higher creativity performance. Human resource flexibility is the basic organizational module of flexible management [29]. It can help companies gain competitive advantages [30]. As revealed by research, human resource flexibility is a way to improve organization performance, serving as a mediator between relationship-orientated management and organization performance [27]. In terms of the relation between innovation and corporate performance in strategic entrepreneurship, human resource practice flexibility also plays the mediating role [31]. Human resource flexibility lays the foundation for sustainable human resource management. Sustainable human resource management contains the concept of flexibility [8]. One 
dimension of sustainable Human resource management is to achieve a flexible system, which can respond to changes flexibly and quickly [13] and sustain competitive advantages [14]. As a critical soft system, human resource flexibility plays another significant role in helping the organization in achieving innovation. Strengthen the flexibility of employees, match with the goal of sustainable HRM, and ultimately promote the sustainable development of enterprises [8].

Human resource flexibility consists of three dimensions [32]. Skill flexibility refers to intellectual and skillful employees being able to accomplish tasks flexibly when facing a variety of work requirements and organizational tasks. Behavior flexibility refers to having a flexible and broad scope for scripts of working behaviors. Human resource practice flexibility refers to human resource functions being able to promptly and precisely react to emergencies or unstable environments. Human resource flexibility management enables companies to flexibly and promptly mobilize employee knowledge or skill reserves [31], stimulates employees' creativity behaviors, and consequently promotes enterprise innovation. Once cultivating skill and behavior flexibility, employees can flexibly handle challenges at work. Behavior flexibility can facilitate decision-making speed, and abundant behavioral scripts ensure the flexibility of employee decisions. While decision-making speed is found to help prohibit or motivate innovation [33].

In terms of specific connotations, it is not comprehensive to regard it as a single capability, nor can we accurately analyze the correlation between human resource flexibility and other variables. Human resource flexibility does not just attach the concept of flexibility to human resources management activities [34], which is a process resource aggregation and reconstruction. There are also complex interactions between the three dimensions [35]. Because of this concept involves not only the ability and behavior of employees at the individual level but also the way of organizational management, Sancherz [36] has divided it into resource flexibility and coordination flexibility. On this basis, this paper holds that human resources flexibility is an ability to deal with uncertainty formed by the flexible practice of human resources when employees have the flexibility of knowledge and skills. Amabile [37] held the opinion that innovative thinking and ability request the organization to take measures for activation. Employees are the resources for the flexible management of the organization, while the behaviors adopted by the human resource management system are the measures at the organizational level. Human resource flexibility is a concept that needs to be comprehensively considered at the individual level and the organizational level. At present, many researches ignore the individual abilities, behaviors, and values of employees when discussing human resource flexibility. They pay more attention to the role of human resource flexibility in an organization's innovation, while rare research in employee creativity performance. The multi-level application of the concept of human resource flexibility is expanded.

\subsection{Work Values and Employee Creativitiy Performance}

Locke [33] thought that organizational culture manipulated employee behaviors by employee work values. As pointed out by Shalley et al. [38], there exists an intimate association between work values and individual working performance. The difference in work values affects employees' cognition toward their job duties and responsibilities [39]. Employees guided by different value have sensitive attitudes towards flexible management. In this paper, we propose that work value provides strong motivation for employees to achieve creativity performance. Work values refer to the intrinsic demands and extrinsic working properties relied on by individuals to strive for achievements. In addition to the influence on employees' self-recognition and self-assessment at work, work values simultaneously guide employees to set different requirements on the working environment and working contents. By reference to existing studies, Robinson [40] indicated work values act as principles to instruct employees to make choices and assessments on working behaviors. Kaplan et al. [41] pointed out that work values were tightly bound up with employees' working motivation. Employees with different values have a different output in the face of working tasks and goals, and also different performance in creativity. Companies might manipulate employees' working attitudes by instructing their work 
values, as attitudes showed a decisive role in behaviors. In this sense, work values ought to be treated as a crucial factor to investigate the configuration of employee creativity performance. Different training methods for employees with different values are ways to develop sustainable HRM [42]. One of the goals of sustainable development is to balance employees' work values and work behavior [14]. According to the values of employees, enterprises adopt corresponding incentive policies, which can stimulate employee creativity performance.

According to Meyer [43], work value consists of three dimensions including comfort and security, competence and growth, and status and independence. As illustrated by Ren et al. [44], status and independence-orientation employees showed higher innovation spirits. Employees with intense status and independence values usually had higher pursuits, and innovation behaviors would better satisfy their spiritual demands [45]. Also, competence and growth value positively influence employee creativity behaviors [45].

The interactionist model of creativity proposed by Woodmn et al. [46] shows that employee creativity performance is a product of the combination of personal attributes and contextual variables. The influential factors of employee creativity performance fall into two levels including organization context and individual [47]. With flexible management and incentive policies of human resources [38], organizations are able to create scenarios beneficial to employees' innovation behaviors [48]. Additionally, Adeler [49] suggested that intrinsic and identified motivations have effects on individual creativity performance. Individuals who are influenced by intrinsic motivation intend to seek creativity, and they could have a high contribution to the creative work [37].

Employee creativity performance is a comprehensive phenomenon, which is influenced by multiple factors. Employees with creative ability have different creativity performance driven by different work values. Individuals are carriers of human resource policies, according to trait activation theory [50], management activities can enhance or weaken the influence of traits on individual behaviors. If the management situation matches with the individual, it will be beneficial to the expression of individual characteristics; otherwise, it will weaken the individual behavior. Therefore, we explored the synergistic effect of work values and human resource flexibility using the fsQCA method. This method does not discuss the correlation between variables, path coefficients, and significance as the structural equation model and regression analysis mentioned in the previous literature, but shows the combination of factors and the importance of different factors in the results.

\section{Materials and Methods}

\subsection{Research Design}

This paper conducts a configuration analysis to explore the core factors of employee creativity performance from human resource flexibility and work values. It reveals the configurative antecedent of employee creativity performance. We included three dimensions of human resource flexibility (i.e., employee skill flexibility, employee behavior flexibility, human resource practice flexibility) and three dimensions of work values (i.e., comfort and security, competence and growth, status and independence) and take age, gender, education, and the industry as control variables. We adapted the questionnaires in small- and medium-sized enterprises located in China. Compared with large-sized enterprises in the same industry, small- and medium-sized enterprises have the characteristics of a relatively small number of employees, small asset scale, and business scope. Economics of scale is the advantage of larger-sized enterprises, while small- and medium-sized enterprises are more flexible in the management system and organizational structure. Small- and medium-sized enterprises are playing an increasingly important role in the national economy. The promotion of technological innovation ability of small- and medium-sized enterprises is an important driving force of supply-side reform in China and an essential source of accelerating economic development and stabilizing employment. Therefore, this paper will collect samples from small- and medium-sized enterprises, and the scale of selected enterprises is all under 1500 people. 


\subsection{Research Framework}

Rooted in the interactive model of creativity, we believe that employee creativity is generated by the interaction between individual employees and relevant management situations. In this paper, we mainly focus on the organizational context aspect and individual aspect. Specifically, organization context refers to human resource practice; individual level contains behavior flexibility, skill flexibility, and three types of work values. According to the trait motivation theory, in different situations, the characteristics of employees will be stimulated to different degrees, and the results will be different. Therefore, we aim to explore which values can play a better role in promoting creativity in the context of human resources flexibility. From these two theory perspectives, this paper involves three dimensions of work value to explore the synergistic role of different human resource flexibility and work value in employee's creativity performance. The framework of this paper is shown in Figure 1. We bridge the gap by testing the synergistic effects of human resource flexibility and work value to demonstrate how the organization and individuals work together to influence employee creativity performance. The solution to this problem can also help managers better integrate enterprise resources to achieve sustainability.

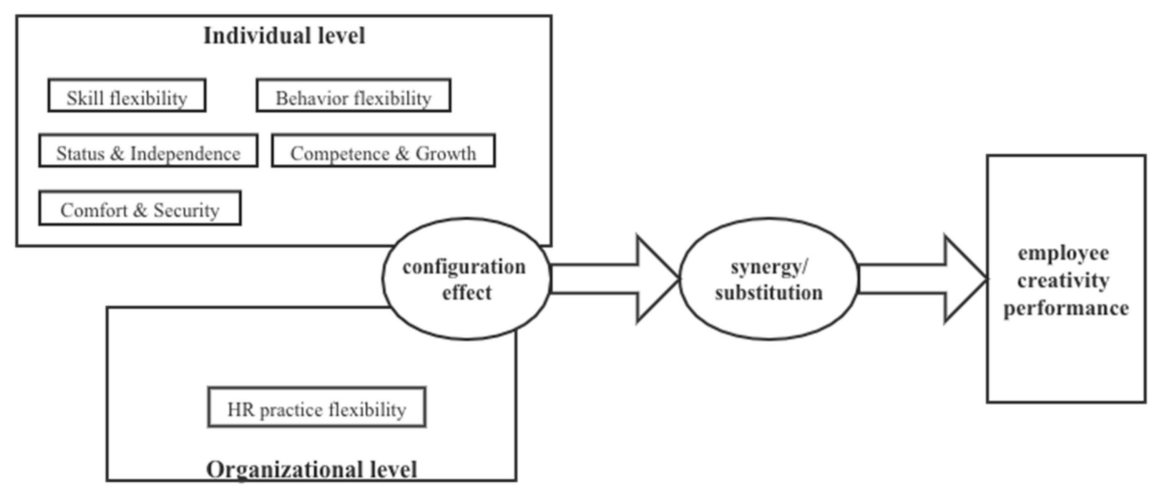

Figure 1. Research framework.

\section{3. fsQCA Method}

This paper adopted a fuzzy-set qualitative comparative analysis (fsQCA) to identify the core components of creativity. FsQCA reveals multiple pathways to employee creativity performance and exposes the key antecedents that provide preconditions for employee creativity performance. Qualitative comparison analysis (QCA) method can explain how conditional factors associate with results. Moreover, it further explores how the above influential factors act on employee creativity performance. A complete full framework should be established to discuss factors of the outcome. FsQCA is fundamentally different from the traditional statistical method, while the regression analysis method focuses on the analysis of factor interaction influence [51]. FsQCA method is outcome-oriented. Path analysis for sophisticated outcomes is achieved through recognizing the combination of different factors leading to the same outcome [52].

Beginning with the perspective of set theory, it investigates the relation between the conditional set and results and uses Boolean algebra algorithm to conduct a formal analysis on problematic logic. If set $X$ is contained in set $Y$, then $X$ is sufficient for $Y$. In order to compute the necessary and sufficient conditions, researchers rely on consistency and coverage measures ranging from 0 to 1 [51]. Equations (1) and (2) of fuzzy set-theoretic consistency and coverage is done as follows:

$$
\begin{gathered}
\text { Consistency }(\mathrm{X} \subseteq \mathrm{Y})=\Sigma \min \left(\mathrm{Xi}_{\mathrm{i}} \mathrm{Yi}\right) \Sigma \mathrm{Xi} \\
\text { Coverage }(\mathrm{X} \subseteq \mathrm{Y})=\Sigma \min \left(\mathrm{Xi}_{\mathrm{i}}, \mathrm{Yi}\right) \Sigma \mathrm{Yi}
\end{gathered}
$$


where $X_{i}$ is the degree of membership of individual $i$ in configuration $X$ and $Y i$ is its degree of membership in outcome Y. Equations (3) and (4) are done as follows: consistency indicates how closely a subset relation is approximated, coverage assesses the degree to which a cause or a causal combination accounts for instances of an outcome [53]. All the solutions comply with the consistency threshold. The character "*" denotes the logical AND, the character " $\sim$ " denotes the condition's absence [51].

$$
\begin{gathered}
P(Y) \subseteq A * B * C * D \\
P(Y) \subseteq \sim A+\sim B+\sim C+\sim D
\end{gathered}
$$

In the previous part, we used theoretical and literature to support every dimension of the variable we want to explore, and as such, we are not randomly conducting experiments. The formation of creativity behaviors is a complex and uncertain process, so we would like to know more about how human resource flexibility and work values work together in this process. Therefore, we did not use the method based on variance theory to explore the relationship between explanatory variables and explanatory variables, but instead used the qualitative comparative analysis method based on set theory to explain this problem.

\subsection{Sample and Procedure}

This research distributed questionnaires to full-time employees in Chinese companies in China and part-time MBA students in China University of Geosciences in Beijing. We used purposive sampling technique to identify the companies. We distributed the questionnaires to eight enterprises that have cooperative relations with our school. With the help of the managers from these companies, we used convenient sampling to identify the respondents from the sampling frame. We collected the questionnaires in two manners. One is online distribution in which the researcher produces the questionnaire and sends the link online to collect data. WenJuanXing made the e-questionnaires. For two weeks, we sent links to middle or senior managers every day by e-mail and WeChat, and then, they sent the questionnaires to the employees in their companies. Three-hundred questionnaires were collected, of which 280 were valid. Another is offline distribution in which the researcher distributed paper questionnaires to MBA students in class. The lecturer assisted us by giving a brief introduction to the purpose of this survey before MBA students completed the survey. We collected data once a week, lasting for three weeks. Each week, we got 30-40 questionnaires. To avoid common method bias, we expressed the items in simple and clear language and collected the questionnaire anonymously. The valid questionnaires were 100 in total from MBA students.

Respondents engaged in multiple fields covering the internet, information communication, new energy application products, finance, banks, and telecommunications. We altogether collected 400 questionnaires, of which 380 questionnaires were valid. The response rate was $95 \%$. Among all respondents, men accounted for $49.1 \%$, and women accounted for $50.9 \%$. As to position composition, most respondents are ordinary employees (68.47\%), and most of them have bachelor's degrees $(56.31 \%)$. Concerning the type of business, most companies specialized in Internet and telecommunication $(37.38 \%)$. The sample's demographic characteristics are shown in Table 1.

\subsection{Measures}

As scales adopted by the paper are all developed in foreign studies, the paper takes translation-back-translation procedures to avoid misunderstanding caused by a discrepancy in semantics.

- Employee creativity performance

A nine-item version by Janssen [54] was taken to measure employee creative performance $(\alpha=0.909)$. Sample items were "creating new ideas for improvements"; "generating original solutions to problems" (1: "not at all characteristic"; 5: "very characteristic"). 
- Human resource flexibility

A fifteen-item version by Bhattacharya et al. [32] was used to measure human resource flexibility ( $\alpha=0.893$ ). Additionally, the variable contained three dimensions: skill flexibility, behavior flexibility, and HR practice flexibility. The sample items are "Our firm can shift employees to different jobs when needed"; "Many employees in our firm have multiple skills that are used in various jobs" (1: "not at all characteristic"; 5: "very characteristic").

- Work values

A twenty-item version by Meyer [43] was utilized to measure work values $(\alpha=0.903)$. Meanwhile, the variable contained three dimensions: 'comfort and security,' 'competence and growth,' 'status and independence'. Sample items were "Permits a routine in time and place of work"; "Requires meeting and speaking with many other people" (1: "strongly disagree"; 5 : "strongly agree").

- Control variable measurement

According to the studies conducted by former scholars, they mostly take employee gender, education background-position, and industry property [55] as the control variables for avoiding the influence of other disturbance variables on research results. Therefore, this paper also takes the above variables as control variables. In dummy variable processing on gender, " 1 " represents men, and " 0 " represents women. Industry property falls into the labor-intensive industry, capital intensive industry, and knowledge-intensive industry. Education background falls into three levels, namely junior college, regular college, master, and above. The position falls into four levels, namely ordinary employees, department managers, middle managers, and senior managers.

Table 1. Sample characteristics $(\mathrm{N}=380)$.

\begin{tabular}{cccc}
\hline & & Number & Frequency (\%) \\
\hline \multirow{2}{*}{ Gender } & Male & 186 & $49.1 \%$ \\
& Female & 194 & $50.9 \%$ \\
\hline \multirow{2}{*}{ Age } & Under 24 years & 133 & $35 \%$ \\
& Above 24 years & 247 & $65 \%$ \\
\hline Position & Below undergraduate & 30 & $7.89 \%$ \\
& Undergraduate & 210 & $55.26 \%$ \\
& Postgraduate and above & 140 & $36.84 \%$ \\
\hline \multirow{2}{*}{ Industry } & Ordinary staff & 256 & $67.54 \%$ \\
& Departments managers & 48 & $12.72 \%$ \\
& Middle managers & 40 & $10.53 \%$ \\
& Senior managers & 36 & $9.21 \%$ \\
\hline Scale & New energy application product & 111 & $29.42 \%$ \\
& Finance services and bank & 127 & $33.2 \%$ \\
& Internet and telecommunication & 142 & $37.38 \%$ \\
\hline & Under 100 people & 80 & $21.49 \%$ \\
& $100-300$ people & 78 & $18.86 \%$ \\
& 300-600 people & 44 & $11.84 \%$ \\
& $600-1000$ people & 34 & $9.21 \%$ \\
& $1000-1500$ people & 144 & $38.6 \%$ \\
\hline
\end{tabular}

\section{Results}

Analyses were in two steps. First, the reliability and validity of measures were examined using SPSS (IBM Corporation, New York, NY, USA) and AMOS ((IBM Corporation, New York, NY, USA). Second, the qualitative comparison analysis was conducted using fsQCA 3.0 (University of California, Irvine, CA, USA). 


\subsection{Testing of Reliability and Validity}

Table 2 shows the summary statistics for the scales, including the means, standard deviations, and maximum and minimum. We used AMOS to conduct confirmatory factor analysis (CFA) to assess the construct discrimination. As shown in Appendix A, the factor loading of all the items were more significant than 0.6. Table 3 shows the Cronbach Alpha, composite reliability, and average variance extracted (AVE). The AVE of transformational leadership was 0.62 , skill flexibility was 0.732 , behavior flexibility was 0.838 , human resource practice flexibility was 0.875 , comfort and security value was 0.862 , competence and growth value was 0.752 , status and independence value was 0.82 , and employee's creative performance was 0.67 . The composite reliability (CR) of transformational leadership was 0.95 , skill flexibility was 0.86 , behavior flexibility was 0.90 , human practice flexibility was 0.87 , comfort and security was 0.91 , competence and growth was 0.91 , and status and independence was 0.90 . Moreover, employee creativity performance was 0.98 . Factor loadings, AVE value, and CR results indicate convergent validity of the measurements was well established. According to Harman's single factor test, if common method variance exists, a single factor can account for all the variables in the research. Three factors were identified, the main factors accounted for $29.267 \%$, and none of the factors explained more than $50 \%$ of the variance, suggesting that common method variance did not exist in our study [56].

Table 2. Mean, Standard Deviation, Maximum and Minimum.

\begin{tabular}{ccccc}
\hline Variable & Mean & SD & Min & Max \\
\hline Skill flexibility & 4.11 & 0.86 & 1.25 & 5 \\
Behavior flexibility & 4.12 & 0.87 & 1 & 5 \\
HR practice flexibility & 4.03 & 0.90 & 1 & 5 \\
Comfort \& Security & 4.25 & 0.63 & 1.4 & 5 \\
Independence \& Status & 4.29 & 0.67 & 0.60 & 5 \\
Competence \& Growth & 4.1 & 0.61 & 1.5 & 5 \\
employee creativity & 4.17 & 0.75 & 0.80 & 5 \\
performance & 1.49 & 0.50 & 1 & 2 \\
Gender & 2.23 & 0.61 & 1 & 3 \\
Education & 1.57 & 0.96 & 1 & 4 \\
Position & 2.11 & 0.74 & 1 & 3 \\
Industry & & & &
\end{tabular}

Table 3. Cronbach Alpha, Composite Reliability and Average Variance Extracted.

\begin{tabular}{cccc}
\hline Variable & Cronbach Alpha & CR & AVE \\
\hline Employee creativity performance & 0.91 & 0.98 & 0.67 \\
Skill flexibility & 0.92 & 0.86 & 0.73 \\
Behavior flexibility & 0.85 & 0.90 & 0.83 \\
HR practice flexibility & 0.89 & 0.87 & 0.88 \\
Comfort \& Security & 0.91 & 0.91 & 0.86 \\
Competence \& Growth & 0.88 & 0.91 & 0.75 \\
Status \& Independence & 0.92 & 0.90 & 0.82 \\
\hline
\end{tabular}

We checked the multicollinearity through the variance inflation factor and tolerance for all the variables, as shown in Table 4. The VIF values were between 1.245 and 1.798, so there were no multicollinearity problems. 
Table 4. Variance Inflation Factor and Tolerance.

\begin{tabular}{ccc}
\hline Variable & VIF & Tolerance \\
\hline Employee creativity performance & 1.25 & 0.75 \\
Skill flexibility & 1.245 & 0.70 \\
Behavior flexibility & 1.768 & 0.82 \\
HR practice flexibility & 1.374 & 0.83 \\
Comfort \& Security & 1.356 & 0.73 \\
Competence \& Growth & 1.604 & 0.69 \\
Status \& Independence & 1.798 & 0.78 \\
\hline
\end{tabular}

\subsection{Calibration}

We used fsQCA to calibrate the data. The producer was following the method proposed by Ragin [51]. The fuzzy-set values for antecedent conditions range from 0 to 1 . With 0 for non-membership and 1 for full membership. 0.5 is the crossover point of membership. In order to ensure the objectivity of the calibration process, the quantiles 25,50 , and 75 of continuous variables are divided into complete non-membership degree, the crossover point and complete membership degree [53]. Table 5 showed that data calibration cut-off points chose.

Table 5. Calibration cut-offs.

\begin{tabular}{cccc}
\hline Variable & Fully in & Crossover Point & Fully Out \\
\hline Skill flexibility & 3.5 & 4 & 4.95 \\
Behavior flexibility & 3.25 & 4.25 & 4.95 \\
HR practice flexibility & 3.33 & 4 & 4.9 \\
Comfort \& Security & 3.8 & 4.4 & 4.75 \\
Independence \& Status & 3.85 & 4.42 & 4.85 \\
Competence \& Growth & 3.75 & 4.25 & 4.5 \\
Employee creativity performance & 3.67 & 4 & 4.95 \\
Gender & 1 & 1 & 2 \\
Education & 2 & 2 & 3 \\
Position & 1 & 1 & 2 \\
Industry & 2 & 2 & 3 \\
\hline
\end{tabular}

\subsection{QCA Results}

Before we do the fsQCA, we conducted necessity analysis, which revealed that all causal conditions showed $<0.85$ consistency, which is below the 0.90 thresholds deemed to establish the existence of a necessary condition [51]. If an antecedent element is a necessary condition for the interpretation result, it shows that the antecedent condition configuration includes the antecedent element, and it is not necessary to include it in the qualitative comparative analysis. Given this, this paper makes a path analysis of the combination of the above factors. Necessity analysis results are as shown in Table 6.

In the process of analysis, the consistency threshold value was set to be 0.8 , an acceptable number of case is 1 . Sufficiency analysis resulted in 7 configurations for employee creativity performance with solution coverage of 0.825 . The solution consistency was 0.786 . Theses 7 high-consistency configurations are shown in Table 7 and will be explained subsequently. The consistency for single path ranged from 0.87 to 0.94 . The raw coverage for single path ranged from 0.13 to 0.67 . 
Table 6. Analysis of conditions.

\begin{tabular}{ccc}
\hline Variable & Consistency & Coverage \\
\hline Skill flexibility & 0.802 & 0.813 \\
$\sim$ Skill flexibility & 0.324 & 0.290 \\
Behavior flexibility & 0.825 & 0.816 \\
$\sim$ Behavior flexibility & 0.305 & 0.280 \\
HR practice flexibility & 0.789 & 0.802 \\
$\sim$ HR practice flexibility & 0.350 & 0.313 \\
Comfort \& Security & 0.786 & 0.752 \\
$\sim$ Comfort \& Security & 0.318 & 0.302 \\
Independence \& Status & 0.779 & 0.835 \\
$\sim$ Independence \& Status & 0.371 & 0.317 \\
Competence \& Growth & 0.758 & 0.709 \\
$\sim$ Competence \& Growth & 0.360 & 0.349 \\
Gender & 0.352 & 0.602 \\
Education & 0.390 & 0.620 \\
Position & 0.475 & 0.647 \\
Industry & 0.309 & 0.624 \\
\hline
\end{tabular}

Table 7. Combinations of conditions of sufficiency.

\begin{tabular}{|c|c|c|c|c|c|c|c|}
\hline \multirow{2}{*}{ Conditions } & \multicolumn{7}{|c|}{ Employee Creativity Performance } \\
\hline & 1 & 2 & 3 & 4 & 5 & 6 & 7 \\
\hline Behavior flexibility & 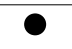 & $\bullet$ & $\boldsymbol{0}$ & $\boldsymbol{0}$ & & 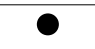 & $\otimes$ \\
\hline Skill flexibility & - & & - & & $\otimes$ & - & - \\
\hline $\begin{array}{l}\text { Human resource } \\
\text { flexibility }\end{array}$ & $\bullet$ & & & $\bullet$ & $\bullet$ & $\bullet$ & $\otimes$ \\
\hline Comfort and security & & & $\bullet$ & $\otimes$ & & & $\bullet$ \\
\hline $\begin{array}{l}\text { Competence and } \\
\text { growth }\end{array}$ & & $\bullet$ & & & $\bullet$ & $\bullet$ & \\
\hline $\begin{array}{l}\text { Status and } \\
\text { independence }\end{array}$ & & $\bullet$ & $\otimes$ & $\bullet$ & - & & $\bullet$ \\
\hline Gender & & & & & & $\bullet$ & - \\
\hline Education & $\bullet$ & - & $\bullet$ & $\bullet$ & $\bullet$ & $\bullet$ & \\
\hline Industry & $\bullet$ & & $\bullet$ & & $\bullet$ & $\bullet$ & $\bullet$ \\
\hline Position & & $\bullet$ & $\bullet$ & $\bullet$ & & & $\bullet$ \\
\hline Consistency & 0.88 & 0.89 & 0.92 & 0.91 & 0.94 & 0.87 & 0.90 \\
\hline Raw coverage & 0.67 & 0.61 & 0.17 & 0.16 & 0.205 & 0.18 & 0.13 \\
\hline Unique coverage & 0.06 & 0.060 & 0.008 & 0.007 & 0.004 & 0.017 & 0.004 \\
\hline Overall consistency & & & & 0.834 & & & \\
\hline Overall coverage & & & & 0.836 & & & \\
\hline
\end{tabular}

Note: $\bullet$ or $\bullet$ means the validity of condition, $\otimes$ or $\otimes$ means the invalidity of condition, blank means the condition is either valid or invalid in the structure, $\bullet$ or $\otimes$ means core condition, and $\bullet$ or $\otimes$ means auxiliary condition, and $\bullet$ or $\otimes$ means auxiliary condition, blank spaces indicate is unimportant for that particular configuration [19].

The introduction of a consistency measure assesses the degree of conformity with necessity/sufficiency hypotheses [57]. Raw coverage measures the extent to which the configurations account for the outcome [51]. For instance, Solution 1 accounts for $67 \%$ of the cases associated with the outcome. Unique coverage measures the proportion of memberships in the outcome explained solely by each configuration.

Among all the listed factors, employee behavior flexibility, status, and independence are the core factors. In the first path (employee behavior flexibility* human resource practice flexibility* employee skill behavior), employee behavior flexibility is the core factor. In the second path (employee behavior flexibility* competence and growth* status and independence), employee behavior flexibility, status and independence are the core factors. In the third path (employee behavior flexibility* human resource practice flexibility*status and independence* $\sim$ comport and security), status and independence, employee behavior flexibility are the core factors. In the fourth path (employee behavior flexibility* 
human resource practice flexibility* $\sim$ status and independence, comport and security), $\sim$ status and independence, employee behavior flexibility are the core factors. In the fifth path ( employee skill behavior* human resource flexibility* status and independence* ${ }^{*}$ competence and growth), status and independence are the core factor. In the sixth path (employee skill flexibility* employee behavior flexibility* human resource practice flexibility* competence and growth), employee behavior flexibility is the core factor. In the seventh path (employee skill flexibility* $\sim$ behavior flexibility* $\sim$ human resource flexibility* status and independence* comfort and security), employee behavior flexibility and status and independence are the core factors.

\section{Discussion}

Using the fsQCA method, we explored the mechanism of human resource flexibility and work values on employee creativity performance. The findings reveal that various combinations of factors including skill flexibility, behavior flexibility, human resource practice flexibility, comfort and security, competence and growth, and status and independence determined the employee creativity performance. We will discuss the 7 configurations from three aspects: the core factors of employee creativity performance, the synergistic effects of factors, and the substitution effects of factors.

\subsection{Core Factors of Employee Creativity Performance}

From the parsimonious solution through fsQCA, the core factors of the outcome are employee behavior flexibility and status and independence value. In other words, among the three dimensions of human resource flexibility, employee behavior flexibility is the most determinative factor influencing employee creativity performance. Among the three types of work values, status and independence value produce efficacy creativity performance.

Crosswise comparison of paths shows that three dimensions of human resource flexibility all affect creativity, while employee behavior flexibility is the core factor. Adhering to the target orientation principle, timely high behavior flexibility of employees made self-adjustment to realize creativity purposes [32]. Ketkar [4] suggested that employees with high behavior flexibility can be active under the broad behavior script, responding to the sophisticated condition effectively and quickly. When faced with a new circumstance, employees with behavior flexibility tend to have more effective creativity performance than employees who strictly abide by the regulations. It is because of the unconventional ways that innovative ideas can be stimulated and implemented and eventually promote employee creativity performance. Thus, employee behavior flexibility is the core element, and it appears in all seven configurations.

The analysis results show that status and independence value is another core factor. Employees with status and independence value pursue respect from others and desire work autonomy [49]. The employee will take the initiative to complete tasks and improve work performance to gain recognition of status and the authority to deal with problems independently. In the study of work values and personality traits, there is evidence to provide that employees with openness traits are more likely to be driven by status and independence value [58]. Employees achieve their work goals if they want to gain authority and respect. High creativity performance can reflect employees' value and prove their ability [44]. Employees with status and independence value tend to accomplish the tasks with open minds and creative methods. They will solve problems actively to improve creative performance. Employees with competence and growth value purse work achievement and opportunities by studying and communication. Their efforts are closely related to the specific content of the work [59]. They tend to improve task performance by focusing on enhancing ability when facing complex problems. Thus, in the process of generating innovative ideas, the orientation of competence and growth will not play the most important role. Employees with comfort and security value the comfort and stability of work and are easily satisfied with achievements. They pay more attention to the compliance and implementation of established systems and rules, and tend to reduce extra investment in their work [44]. 
Consequently, there will be less innovative behavior than the other two types of values. To sum up, in the whole process of innovation, the orientation of status and independence are more influential than others. Comfort and security value are found to be a condition only in two paths. Prior studies also proved that comfort and security value inhibit an employee's extra work [60].

\subsection{Synergistic Effects}

As reflected by configuration analysis, organizations can gain creativity results by executing different flexible strategies on employees with various value orientations. There are 7 configurations from fsQCA results, indicating that there is not a single mode to stimulate creativity, which is consistent with the interaction theory of creativity. Employees' skills and behaviors and employees' different values at the individual level interact with human resource practices. The results are further illustrative that creativity is an uncertain and changeable process. Configuration 1 and configuration 2 have a stronger explanatory power than other paths, which implies that it is a critical consideration combination. Configuration 1 implies that when work values are unimportant in this particular path or employees with less distinct values, three dimensions of human resource flexibility will make joint efforts for creativity [9]. In particular, employee behavior flexibility is the core factor. The other two dimensions serve as supplemented factors. As proved by configuration 2 , the combination of a high level of employee behavior flexibility, status, and independence value will lead to creativity performance. Meanwhile, competence and growth value are a subsidiary element in this configuration. When employees performed behavior flexibility, their competence and growth value can be activated more easily, in line with trait activation theory, generating creativity performance. In configuration 6 , the combination indicates the synergistic effects of human resource flexibility and competence and growth value. Employees with strong competence and growth orientation can seize more opportunities at work and devote more time and energy [45]. Meanwhile, they will show more autonomy at work. Accordingly, they need change and variety of duties and activities [43]. Therefore, such employees can better trigger their creativity under the context of a high level of behavior flexibility and skill flexibility. Configuration 7 indicates the combination of employee skill flexibility, status, and independence value leads to creativity. In this combination, status and independence value is the core factor. Employees with a strong value of status and independence will generate creativity behavior to enhance their status and gain authority of work [40]. When organizations pay attention to the training of employees' skills, employees with a strong orientation of status and independence will be serious and diligent at work, display the talent and skill, and ultimately achieve their creativity performance. Employee skill flexibility focuses on the alternative skills that can be used by employees and the multi-skill employees can be deployed fast [61], to accomplish a given task when the task is difficult. It is a resource and ability for organizations to help them approach challenges. Organizations implemented the low level of behavior flexibility and human resource practice flexibility, that is to say there is a complete and strict conduct system. Comfort and security value serve as a co-factor in this configuration. Employees with comfort and security value orientation and focus on their satisfaction in spirits [62], they need a routine in time and place of work [43]. Human resource practice flexibility did not appear in this study, indicating that work arrangement is somewhat regular, which accords with the needs of the above-mentioned employees' working habits.

\subsection{Substitution Effects}

The comparison of path 3 and path 4 indicates that status and independence alongside comfort and security cannot coexist when organizations have human resource flexibility and a high level of employee behavior flexibility. Employees are flexible enough to adjust to changing work requirements. Human recourse practice is changeable to keep path with the competitive environment [32]. In this situation, employees with only one strong value are more adapted to enhance creative performance. Status and independence along with comfort and security are incompatible with each other. Ren et al. [44] considered that comfort and security value would affect employees' relationships with others and 
pursuits for the workplace, which consequently weakened their initiative in creativity performance. When the environment requires employees and organizations to adjust fast, the values of pursuing clear and strict rules are contradictory to those of pursing job autonomy. Zhan et al. [60] proved that comfort and security value has a negative impact on work engagement, while employees with independence and status values are willing to make extra work efforts.

The comparison of factors in path 3 and path 4 shows that when an organization implements different levels of skill flexibility, creativity will be triggered by different type of work values. When organizations do not implement skill flexibility, the core factor is status and independence, and conversely, when organizations implement skill flexibility, creativity will be triggered by competence and growth. Organizations reinforce skill flexibility so that employees can concentrate more on individual ability growth, entire career building, and fully exert individual talents [63], which is consistent with targets of competence and growth value.

\section{Implications and Research Limitations}

\subsection{Theoretical Implications}

This study has three theoretical implications. Firstly, the research expands content in the employee creativity performance field. This paper is the first to discuss the relationship between human resource flexibility and employee creativity performance, verify the positive influences of human resource flexibility on employee creativity performance, and expand and enrich the antecedent's factors of creativity theory. Furthermore, the results of this paper show the core factor that stimulates creativity among the three dimensions. This study opens the black box from a new insight by showing the configurations of creativity and further advances in the research on human resource flexibility and employee creativity performance.

Secondly, this research considers the combined effects of work values and human resource flexibility on employee creativity performance, complementing the entire structure. Employees with competence and growth value orientation focus on the training of their abilities and expect to realize self-pursuit at a higher level. Besides, employees with status and independence along with value orientation seek self-growth and have substantial autonomy at work [24]. We found multiple configurations to employee creativity performance, which indicates that employees with different work values will have different choices for creativity. Thus, our study makes contributions to the employee creativity performance literature by showing the combination of various types of work values and human resource flexibility.

Thirdly, the fsQCA method has been used to observe the combination of multiple factors. We used fsQCA to clarify the antecedent model of employee creativity performance. Creativity behavior is a sophisticated phenomenon. The contribution of this study is using fsQCA to expand the creativity theory. The research can better interpret the influence of human resource flexibility on employee creativity behaviors after taking multiple combination paths into account. The methodology is the combination of qualitative and quantitative methods, which is another logical approach to explain the relationship between variables. Compared with the regression approach, the qualitative comparison analysis results can find the core factor and multiple factors combinations that lead to the outcome. We have contributed to the creativity theory building by suggesting a combination of human resource flexibility and work values. FsQCA does not provide a causal relationship between the above variables. Moreover, it not only compensates the logic limitations of empirical studies but also enriches the methodology about creativity theory.

\subsection{Practical Implications}

In order to adapt to external and internal environment changes, and seek sustainable development, small- and medium-sized enterprises should maintain the ability of innovation. The conclusion of this paper also provides specific management methods for how to promote the sustainable development 
of enterprises in the sustainable system of human resources. Organizations should take proper flexible management measures to motivate employee innovation and offer necessary support to employees' expansion of knowledge and skills. Moreover, they should also attempt to reinforce human resource practice flexibility by adding employee work practice, providing fair returns, and following developmental assessment means [21], correctly assess employee abilities, and establish high-participation working system to cultivate employee behavior flexibility, encourage employees to learn new skills, promote their level and enhance skill flexibility. The flexible management strategies are of great significance for innovation.

As indicated by research conclusions, different work values will create various influences under different conditions. Human resource practice should take how employees' specific work values into consideration. Managers should implement proper management modes for different types of employees. Employees with competence and growth orientation expect to boost their power and gain growth and exercise. While employees with status and independence value orientation expect to gain autonomy throughout their efforts, at this point, managers ought to foster their skill flexibility and behavior flexibility to encourage employees. Organizations have to match employees with positions and pay great attention to individual employee interests, self-growth, self-realization, and many other factors, consequently ensuring that employees are passionate at work and better realize work innovation.

\subsection{Research Limitations and Future Research Directions}

Firstly, we collected data from one subject. Though the paper passes the common method bias test, common method bias could better be controlled via a more rigorous measurement flow. Subsequent studies may adopt a matching method to distribute questionnaires or a tracking survey method to ensure data quality. Secondly, as the data is cross-section data instead of vertical data, the research lacks robustness. Thirdly, future studies may take leadership style as a significant variable. The research in the future should further deepen the relationship between leadership style and human resource flexibility. This study is conducted in the context of China, the results need to be generalized by conducting comparative studies.

\section{Conclusions}

This study collected 380 questionnaires and conducted the data by using the fsQCA method, and drew the following three conclusions. Firstly, employee behavior flexibility along with status and independence values are the core factors of employee creativity performance. Secondly, three dimensions of human resource flexibility have synergistic effects (a high level of behavior flexibility with status and independence value have synergistic effects; a high level of skill flexibility with competence and growth value have the synergistic effects). Thirdly, when employees have a high level of behavior flexibility, status and independence value have the substitution effects of comfort and security value; when employees have different degrees of skill flexibility, status and independence value have the substitution effects of competence and growth value. On this basis, managers can take appropriate measures according to different flexible abilities and work values of employees to improve their creativity performance and ultimately achieve sustainable development of the enterprise.

Author Contributions: Conceptualization, S.G., and Y.S.; methodology, S.G. and Y.S.; software, Y.S.; validation, Y.Z. and S.S.G.; investigation, Y.S.; writing一original draft preparation, S.Y.; writing-review and editing, Y.Z.; supervision, Y.Z. and S.G. All authors have read and agreed to the published version of the manuscript.

Funding: This research received no external funding.

Conflicts of Interest: The authors declare no conflicts of interest. 


\section{Appendix A}

Table A1. Questionnaires.

\begin{tabular}{|c|c|c|}
\hline Variable & Item & $\lambda$ \\
\hline \multirow{8}{*}{$\begin{array}{l}\text { Employee creativity } \\
\text { performance }\end{array}$} & Creating new ideas for difficult issues & 0.69 \\
\hline & Searching out new working methods, techniques or instruments & 0.67 \\
\hline & Generating original solutions for problems & 0.70 \\
\hline & Mobilizing support for innovative ideas & 0.71 \\
\hline & Making important organizational members enthusiastic for innovative ideas & 0.72 \\
\hline & Transforming innovative ideas into useful applications & 0.74 \\
\hline & Introducing innovative ideas into the work environment in a systemic way & 0.68 \\
\hline & Evaluating the utility of innovative ideas & 0.68 \\
\hline \multirow{6}{*}{ Skill flexibility } & I can shift myself to different jobs when needed & 0.74 \\
\hline & I can switch to new jobs in our company within a short time & 0.67 \\
\hline & I am capable of putting new skills to use within a short time & 0.65 \\
\hline & I have a broad variety of skills to finish work tasks & 0.69 \\
\hline & Many employees in our firm have multiple skills that are used in various jobs & 0.78 \\
\hline & I can learn new skills within a short period & 0.74 \\
\hline \multirow{8}{*}{ Behavior flexibility } & The flexibility of my work habits helps to change according to market demands & 0.81 \\
\hline & I can change work habits in response to changes in the competitive environment & 0.62 \\
\hline & Our employees respond to changing situations within a short time & 0.66 \\
\hline & $\begin{array}{l}\text { I readily change work habits as demanded by changes in the } \\
\text { working environment }\end{array}$ & 0.69 \\
\hline & I am flexible enough to adjust to dynamic work requirements & 0.65 \\
\hline & Our employees adjust to changing work requirements within a short period & 0.73 \\
\hline & My response to the changing nature helps us remain competitive & 0.82 \\
\hline & I change their behavior in response to customer requirements & 0.86 \\
\hline \multirow{7}{*}{ HR practice flexibility } & $\begin{array}{c}\text { The flexibility of our HR practices helps us to adjust to the changing demands } \\
\text { of the environment }\end{array}$ & 0.64 \\
\hline & $\begin{array}{c}\text { Our firm modifies its HR system to keep pace with the changing } \\
\text { competitive environment }\end{array}$ & 0.74 \\
\hline & HR practice parameters adjust quickly to changes in business conditions & 0.78 \\
\hline & We make frequent changes in our HR practices to align the HR system & 0.76 \\
\hline & Changes in our HR practices enable us to remain competitive in the market & 0.79 \\
\hline & Our HR practices adjust meaningfully to changing business scenarios & 0.65 \\
\hline & Our HR practices, as a whole, are flexible & 0.60 \\
\hline \multirow{5}{*}{ Comfort \& Security } & Permits a regular routine in time and place of work & 0.78 \\
\hline & Provides job security & 0.79 \\
\hline & Has clear-cut rules and procedures to follow & 0.80 \\
\hline & Provides comfortable working conditions & 0.79 \\
\hline & Provides ample leisure time off the job & 0.76 \\
\hline \multirow{9}{*}{ Competence \& Growth } & Requires meeting and speaking with many other people & 0.76 \\
\hline & Is intellectually stimulating & 0.75 \\
\hline & Requires originality and creativeness & 0.74 \\
\hline & Makes a social contribution by the work you do & 0.71 \\
\hline & Satisfies your cultural and aesthetic interests & 0.70 \\
\hline & Encourages continued development of knowledge and skills & 0.91 \\
\hline & Permits you to develop your own methods of doing the work & 0.82 \\
\hline & Provides a feeling of accomplishment & 0.84 \\
\hline & Provides change and variety in duties and activities & 0.77 \\
\hline \multirow{7}{*}{ Status \& Independence } & Permits advancement to high administrative responsibility & 0.85 \\
\hline & Provides the opportunity to earn a high income & 0.85 \\
\hline & Requires supervising others & 0.82 \\
\hline & Permits working independently & 0.77 \\
\hline & Is respected by other people & 0.76 \\
\hline & Requires working on problems of central importance to the organization & 0.75 \\
\hline & Gives you the responsibility for taking risks & 0.75 \\
\hline
\end{tabular}




\section{References}

1. Chu, Z.; Liu, C.; Li, G.; Guan, K. Sustainable development of the economic circle around Beijing: A view of regional economic disparity. Sustainability 2018, 10, 3691. [CrossRef]

2. Abolhassan Halati, Y.H. Intersection of economic and environmental goals of sustainable development initiatives. J. Clean. Prod. 2018, 189, 813-829. [CrossRef]

3. Lee, J.; Kim, S.; Lee, J.; Moon, S. Enhancing employee creativity for a sustainable competitive advantage through perceived human resource management practices and trust in management. Sustainability 2019, 11, 2305. [CrossRef]

4. Obiwulu, S.U.; Yunus, E.M.; Ibrahim, F.; Zuruzi, A.S. Sustaining innovation: Creativity among employees of small and medium-sized enterprises and students in higher education institutions in Brunei Darussalam. J. Open Innov. Technol. Mark. Complex. 2019, 5, 25. [CrossRef]

5. Arefieva, O.; Piletska, S.; Arefiev, S. The innovative activity of enterprises as a prerequisite for sustainable economic development. Balt. J. Econ. Stud. 2018, 4, 1-7. [CrossRef]

6. Janssen, O. Job demands, perceptions of effort-reward fairness and innovative work behaviour. J. Occup. Organ. Psychol. 2000, 73, 287-302. [CrossRef]

7. Zhang, X.; Bartol, K.M. Linking empowering leadership and employee creativity: The influence of psychological empowerment, intrinsic motivation, and creative process engagement. Acad. Manag. J. 2010, 53, 107-128. [CrossRef]

8. Aust, I.; Matthews, B.; Muller-Camen, M. Common Good HRM: A paradigm shift in Sustainable HRM? Hum. Resour. Manag. Rev. 2019, 100705. [CrossRef]

9. Do, B.R.; Yeh, P.W.; Madsen, J. Exploring the relationship among human resource flexibility, organizational innovation and adaptability culture. Chin. Manag. Stud. 2016, 10, 657-674. [CrossRef]

10. Milliman, J.; Von Glinow, M.A.; Nathan, M. Organizational Life Cycles and Strategic International Human Resource Management in Multinational Companies: Implications for Congruence Theory. Acad. Manag. Rev. 1991, 16, 318-339. [CrossRef]

11. Parker, S.K. From passive to proactive motivation: The importance of flexible role orientations and role breadth self-efficacy. Appl. Psychol. 2000, 49, 447-469. [CrossRef]

12. Chadwick, C. Theoretic insights on the nature of performance synergies in human resource systems: Toward greater precision. Hum. Resour. Manag. Rev. 2010, 20, 85-101. [CrossRef]

13. King, K.A. The talent climate: Creating an organisational context supportive of sustainable talent development through implementation of a strong talent system. J. Organ. Eff. 2017, 4, 298-314. [CrossRef]

14. Mazur, B. Sustainable Human Resource Management in theory and practice. Ekon. I Zarzadzanie 2014, 6, 158-170.

15. Zolin, R.; Kuckertz, A.; Kautonen, T. Human resource flexibility and strong ties in entrepreneurial teams. J. Bus. Res. 2011, 64, 1097-1103. [CrossRef]

16. Elizur, D. Facets of work values: A structural analysis of work outcomes. J. Appl. Psychol. 1984, 69, 379-389. [CrossRef]

17. Schweisfurth, T.G.; Raasch, C. Absorptive capacity for need knowledge: Antecedents and effects for employee innovativeness. Res. Policy 2018, 47, 687-699. [CrossRef]

18. Grandori, A.; Furnari, S. A chemistry of organization: Combinatory analysis and design. Organ. Stud. 2008, 29, 459-485. [CrossRef]

19. Fiss, P.C. Building better causal theories: A fuzzy set approach to typologies in organization research. Acad. Manag. J. 2011, 54, 393-420. [CrossRef]

20. Varadarajan, R. Innovating for sustainability: A framework for sustainable innovations and a model of sustainable innovations orientation. J. Acad. Mark. Sci. 2017, 45, 14-36. [CrossRef]

21. Combs, J.; Liu, Y.; Hall, A.; Ketchen, D. How much do high-performance work practices matter? A meta-analysis of their effects on organizational performance. Pers. Psychol. 2006, 59, 501-528. [CrossRef]

22. Urbaniec, M. Sustainable entrepreneurship: Innovation-related activities in European enterprises. Pol. J. Environ. Stud. 2018, 27, 1773-1779. [CrossRef]

23. Schaltegger, S.; Wagner, M. Sustainable entrepreneurship and sustainability innovation: Categories and interactions. Bus. Strateg. Environ. 2011, 20, 222-237. [CrossRef] 
24. Hegney, D.; Plank, A.; Parker, V. Extrinsic and intrinsic work values: Their impact on job satisfaction in nursing. J. Nurs. Manag. 2006, 14, 271-281. [CrossRef]

25. Sett, P.K. Environmental dynamism, hr flexibility, and firm performance: Analysis of a multi-level causal model. Int. J. Hum. Resour. Manag. 2010, 21, 1173-1206.

26. Jiang, K.; Mckay, P.F.; Lee, T.W.; Mitchell, T.R. When and How Is Job Embeddedness Predictive of Turnover? A Meta-Analytic Investigation. J. Appl. Psychol. 2012, 97, 1077-1096. [CrossRef]

27. Lado, A.A.; Wilson, M.C. Human Resource Systems and Sustained Competitive Advantage: A Competency-Based Perspective. Acad. Manag. Rev. 1994, 19, 699-727. [CrossRef]

28. Kleysen, F.R.; Street, C.T. Toward a multi-dimensional measure of individual innovative behavior. J. Intellect. Cap. 2001, 2, 284-296. [CrossRef]

29. Way, S.A. A firm level analysis of HR flexibility. Available online: https://www.researchgate.net/profile/Sean Way/publication/35448791_A_firm-level_analysis_of_HR_flexibility/links/5af50d28a6fdcc0c030b011a/Afirm-level-analysis-of-HR-flexibility.pdf (accessed on 1 May 2019).

30. Kalleberg, A.L. Organizing flexibility: The flexible firm in a new century. Br. J. Ind. Relat. 2001, 39, 479-504. [CrossRef]

31. Laursen, $\mathrm{K}$. The importance of sectoral differences in the application of complementary HRM practices for innovation performance. Int. J. Econ. Bus. 2002, 9, 139-156. [CrossRef]

32. Bhattacharya, M.; Gibson, D.E.; Doty, D.H. The effects of flexibility in employee skills, employee behaviors, and human resource practices on firm performance. J. Manage. 2005, 31, 622-640. [CrossRef]

33. Locke, E.A.; Latham, G.P. Work Motivation and Satisfaction: Light at the End of the Tunnel. Psychol. Sci. 1990, 1, 240-246. [CrossRef]

34. Way, S.A.; Tracey, J.B.; Fay, C.H.; Wright, P.M.; Snell, S.A.; Chang, S.; Gong, Y. Validation of a Multidimensional HR Flexibility Measure. J. Manage. 2015, 41, 1098-1131. [CrossRef]

35. Eisenhardt, K.M.; Martin, J.A. Dynamic capabilities: What are they? Strateg. Manag. J. 2000, $21,1105-1121$. [CrossRef]

36. Sanchez, R.O.N. Strategic flexibility in product competition. Strateg. Manag. J. 1995, 16, 135-159. [CrossRef]

37. Amabile, T.M. The social psychology of creativity: A componential conceptualization. J. Pers. Soc. Psychol. 1983, 45, 357-376. [CrossRef]

38. Shalley, C.E.; Zhou, J.; Oldham, G.R. The effects of personal and contextual characteristics on creativity: Where should we go from here? J. Manage. 2004, 30, 933-958. [CrossRef]

39. Kirkman, B.L.; Shapiro, D.L.; Kirkman, B.L. The Impact Of Cultural Values On Job Satisfaction And Organizational Commitment In Self-Managing Work Teams: The Mediating Role Of Employee Resistance. Acad. Manag. 2014, 44, 557-569.

40. Robinson, C.H.; Betz, N.E. A psychometric evaluation of super's work values inventory-revised. J. Career Assess. 2008, 16, 456-473. [CrossRef]

41. Kaplan, S.A.; Bradley, J.C.; Joseph, N.; Luchman, D.H. On the Role of Positive and Negative Affectivity in Job Performance: A Meta-Analytic Investigation. Affect. Perform. 2009, 94, 162-176.

42. Boudreau, J.W.; Ramstad, P.M. Talentship talent segmentation, and sustainability: A new HR decision science paradigm for a new strategy definition. Hum. Resour. Manage. 2005, 44, 129-136. [CrossRef]

43. Meyer, J.P.; Irving, P.G.; Allen, N.J. Examination of the combined effects of work values and early work experiences on organizational commitment. J. Organ. Behav. 1998, 19, 29-52. [CrossRef]

44. Hualiang, R.; Dongtao, Y.; Qun, L. The Impact of the Different Work Value Pursuit on Innovation Behavior_RenHualiang.pdf. Sci. Technol. Progess Policy 2016, 33, 103-108.

45. Yanping, L.; Xuanfang, H. Structure of Work Values of Millennial Generation and Mechanism of Its Impact on work Behavior. Econ. Manag. 2012, 34, 77-85.

46. Rogers, C.R. Toward a theory of creativity. Etc A Rev. Gen. Semant. 1993, 11, 249-260.

47. Shin, S.J.; Zhou, J. Transformational leadership, conservation, and creativity: Evidence from Korea. Acad. Manag. J. 2003, 46, 703-714. [CrossRef]

48. Huselid, M.A. The impact of human resource management practices on turnover, productivity, and corporate financial performance. Acad. Manag. J. 1995, 38, 635-872.

49. Adler, P.S.; Chen, C.X. Combining creativity and control: Understanding individual motivation in large-scale collaborative creativity. Account. Organ. Soc. 2011, 36, 63-85. [CrossRef] 
50. Tett, R.P.; Burnett, D.D. A personality trait-based interactionist model of job performance. J. Appl. Psychol. 2003, 88, 500-517. [CrossRef]

51. Charles, C. Ragin Redesigning Social Inquiry: Fuzzy Sets and Beyond. Univ. Chic. Press 2008, 88, 1934-1936.

52. Roig-Tierno, N.; Huarng, K.H.; Ribeiro-Soriano, D. Qualitative comparative analysis: Crisp and fuzzy sets in business and management. J. Bus. Res. 2016, 69, 1261-1264. [CrossRef]

53. Garcia-Castro, R.; Francoeur, C. When more is not better: Complementarities, costs and contingencies in stakeholder management. Strateg. Manag. J. 2016, 37, 406-424. [CrossRef]

54. Janssen, O. Fairness perceptions as a moderator in the curvilinear relationships between job demands, and job performance and job satisfaction. Acad. Manag. J. 2001, 44, 1039-1050.

55. Holmes, P.; Chapman, T.; Ed, D. Employee job embeddedness: Why people stay. Int. J. Bus. Manag. Econ. Res. 2013, 4, 802-813.

56. Podsakoff, P.M.; MacKenzie, S.B.; Lee, J.Y.; Podsakoff, N.P. Common Method Biases in Behavioral Research: A Critical Review of the Literature and Recommended Remedies. J. Appl. Psychol. 2003, 88, 879-903. [CrossRef] [PubMed]

57. Delmas, M.A.; Pekovic, S. Organizational Configurations for Sustainability and Employee Productivity: A Qualitative Comparative Analysis Approach. Bus. Soc. 2018, 57, 216-251. [CrossRef]

58. Wang, Z.; Ma, J.; Chen, Y. Work value and motivation mediate the influence of personality on contextual performance. In Proceedings of the 2013 IEEE International Conference on Industrial Engineering and Engineering Management, Bangkok, Thailand, 10-13 December 2013; pp. 1666-1670.

59. Hao, J.-L.; Yin, M. Can Employee Satisfaction Improvement Surely Improve Job Performance: An Empirical Study Based on Different Work Values. J. Chongqing Technol. Bus. Univ. Soc. Sci. Ed. 2018, 35, 37-45.

60. Zhan, X.; Yang, D.; Luan, Z. The relationship betwen work values and employe voice behavior: The moderating efect of perceived organizational support. Chin. J. Manag. 2016, 14, 133-138.

61. Lee, D.; Jeff, E. In pursuit of marketplace agility: Applying precepts of self-organizing systems to optimize human resource scalability. Hum. Resour. Manag. 2005, 44, 183-188.

62. Lee, T.W.; Mitchell, T.R.; Sablynski, C.J.; Burton, J.P.; Holtom, B.C. The effects of job embeddedness on organizational citizenship, job performance, volitional absences, and voluntary turnover. Acad. Manag. J. 2004, 47, 711-722.

63. Duffy, R.D.; Sedlacek, W.E. The work values of first-year college students: Exploring group differences. Career Dev. Q. 2007, 55, 359-364. [CrossRef] 